\title{
Analysis of the Relationship between the $n$th Root which is a Whole Number and the $n$ Consecutive Odd Numbers
}

\author{
Kwenge Erasmus ${ }^{1, *}$, Mwewa Peter $^{2} \&$ Mulenga H.M ${ }^{3}$ \\ ${ }^{1}$ Mpika Day Secondary School, P.O. Box 450004, Mpika, Zambia \\ ${ }^{2}$ Department of Mathematics and Statistics, Mukuba University, P.O. Box 20382, Itimpi, Kitwe, Zambia \\ ${ }^{3}$ Department of Mathematics, Copperbelt University, P.O. Box 21692, Kitwe, Zambia \\ *Correspondence: Mpika Day Secondary School, P.O. Box 450004, Mpika, Zambia. Tel: 260-976-379-410. E-mail: \\ kwengee@yahoo.com
}

Received: April 22, 2015 Accepted: July 12, $2015 \quad$ Online Published: August 7, 2015

doi:10.5430/jct.v4n2p35 URL: http://dx.doi.org/10.5430/jct.v4n2p35

\begin{abstract}
The study was undertaken to establish the relationship between the roots of the perfect numbers and the $n$ consecutive odd numbers. Odd numbers were arranged in such a way that their sums were either equal to the perfect square number or equal to a cube. The findings on the patterns and relationships of the numbers showed that there was a relationship between the roots of numbers and $\mathrm{n}$ consecutive odd numbers. From these relationships a general formula was derived which can be used to determine the number of consecutive odd numbers that can add up to get the given number and this relationship was used to define the other meaning of $n$th root of a given perfect number from consecutive $n$ odd numbers point of view. If the square root of 4 is 2 , then it means that there are 2 consecutive odd numbers that can add up to 4 , if the cube root of 27 is 3 , then there are 3 consecutive odd number that add up to 27 , if the fifth root of 32 is 5 , then it means that there are 5 consecutive odd numbers that add up to 32 .
\end{abstract}

Keywords: roots of perfect numbers; relationship; consecutive $n$ odd numbers

\section{Introduction}

Mathematics is a discipline that deals with numbers, patterns, relationships and structures of seen and unseen objects to our naked eyes. It is mathematics which enables man to probe and have a full understanding of the universe with the help of numbers. Most people have associated the definition of mathematics to numbers. To them mathematics is about numbers. Numbers have been defined, according to Lankford F.G, Ulrich J.F and Clark J.R (1961), as ideas which are represented by symbols known as numerals. Numbers can also be defined as mathematical tools that exist in our minds which are used for measuring, counting of objects and solving problems. Numbers only exist in our minds because they cannot be seen or touched since they are not tangible. In mathematics, each symbol refers to an idea, a meaning, which exists only in our minds. Numbers cannot be seen or touched but they exist, what can be seen or touched are numerals. Dependence on numbers in the learning of mathematics has made mathematics to be abstract in nature. One cannot learn mathematics without first understanding the meaning of the number itself and its relationship with other numbers and the patterns which these numbers form. For example, to understand the circle fully, one has to know the meaning of $\pi$ and its relationship with the circle. Knowing how to find the numerical value of $\pi$, can make someone see that a circle is a special polygon. This special polygon which hides in the name of the circle with at least 3600000 sides can only be seen if one is able to derive kwenge's formula (Kwenge, 2013) for $\pi$ which is: $\pi=\sin \theta\left(1.8 \times 10^{\mathrm{n}+2}\right)$ where $\theta=10^{-\mathrm{n}}$ (where $\theta$ is equal to 10 raised to power negative $n$ ) and $n$ the number of decimal places of $\pi$ required. Without numbers, mathematics is meaningless and it cannot be understood and appreciated fully. The uniqueness of numbers made the researchers to think of exploring the patterns and relationships between the perfect numbers such as square numbers, cubes and $n$th powers on one side and the consecutive odd numbers on the other side.

Being teachers of mathematics, the researchers had seen that mathematics had been and is still posing a number of challenges to both teachers and learners such that generally the performance in mathematics has not been good compared to other subjects. In order to understand and appreciate mathematics since it is full of abstract; the teacher 
must have sound content subject matter knowledge and pedagogical knowledge (Shulman, 1987) so that he can be resourceful, creative and be able to make models and teaching aids that can facilitate the teaching and learning of mathematics with joy. In mathematics, teachers with sound content knowledge are likely to present problems to the learners in a context that they are familiar with and make a link to the problems to what they already know while those with less mathematics knowledge tend to put emphasis on calculations based on memorizations of procedures rather than on the underlying concepts. According to Zuya E. H (2014), mathematics teachers' ability to probe students' thinking processes is important to effective teaching of mathematics. Teachers can only do this if they have been equipped with pedagogical content knowledge because the quality of the questions asked by teachers plays an important role in identifying learners' difficulties. Moyer and Milewicz (2002) said teachers who are able to ask skillful questions can also analyze the depth of their students' thought better. For Zuya E.H (2014), if a teacher does not have an adequate understanding of the subject-matter, he/she will not be able to ask competent questions that would reveal students' errors and misconceptions.

\subsection{The Purpose}

The purpose of the study was to establish the relationship between the numbers with roots which are whole numbers and the odd numbers, to redefine the meaning of the root of the given number which is perfect in nature, to help the learners and teachers develop critical thinking ability, make the learning and teaching of mathematics be more interesting and also help them to increase their knowledge, skills in mathematics and explore the hidden powers in number patterns.

\subsection{Literature Review}

The main aim of teaching and learning mathematics is to enable the students to develop proficiency with mathematical skills, improve logical thinking, expand understanding of mathematical concepts and promote success (Foster A.G, Rath J.N and Winters L.J., 1986).Learning mathematics without full understanding of the concept of powers is incomplete because at one point or another, one will meet the situation that would demand the knowledge of finding the nth root of a certain number with or without a calculator. The commonest powers that we encounter on the daily basis are the powers of 2 and 3 . If 5 is raised to power 2, then 5 is the base while 2 is the power or index and this expression can be written as $5^{2}$ which is called exponential form. In this case since 2 is the power, then 5 is the square root of 25 because $25=5^{2}=5 \times 5$. According to Foster A.G, Winters L.J, Gell J.M, Rath J.N and Gordon B.W (1995), a square root of a number is defined as: If $x^{2}=y$, then $x$ is a square root of $y$. With Foster et al (1995), an expression like $\sqrt{64}$ is called a radical expression. The symbol $\sqrt{ }$ is a radical sign. All positive real numbers have two square roots; one is the positive ( or principal) square root and the other is the negative square root. The number inside a radical symbol is the radicand (Roland E.L, Timothy D.K and Lee S., 1998).

With Foster A.G, Rath J.N and Winters L.J (1986), for any real numbers $a$ and $b$, and any positive integer $n$, if $a^{n}=b$,

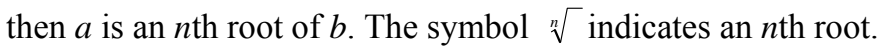

Radical Expression

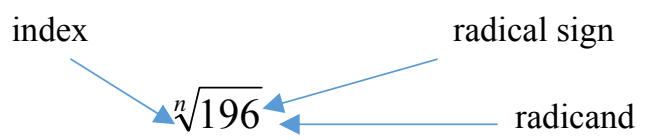

Using number patterns, the learner can be made to understand the meaning of the concept root and know that the root can be defined from addition point of view with respect to consecutive odd numbers. Number patterns can also help learners to know that multiplication is repeated addition and also appreciate what makes $\pi$ be an irrational number. If one has to understand why $\pi$ is irrational, one has to look at the number pattern that leads to the deriving of the formula for $\pi$ which is known as Kwenge's formula for $\pi$ (Kwenge, 2013). For example, if the radius of the circle is $10 \mathrm{~cm}$, then the area of the circle is:

$$
\begin{aligned}
\text { Area of a circle } & =\pi r^{2} \\
& =100 \pi \\
& =314.1592654
\end{aligned}
$$

If $\theta$ is the angle at the centre of an isosceles triangle in a polygon inscribed in a circle and is $9^{0}$, and the equal sides of the triangle is 10 units, then the area of the triangle is; 


$$
\begin{aligned}
\text { Area } & =\frac{1}{2} \mathrm{ab} \sin \theta \text { where } \theta=9^{0} \\
& =\frac{1}{2} \times 10 \times 10 \sin 9^{0} \\
& =7.821723252 .
\end{aligned}
$$

We need to know how many such isosceles triangles with $9^{0}$ at the centre are in the circle with radius $10 \mathrm{~cm}$. To find the number, we need to divide the $360^{\circ}$ by $9^{0}$ which will give us 40 such triangles.

So the total of such triangles $=40 \times 7.821723252$

$$
=312.8689301
$$

Since 312.8689301 is less than the area of the circle, we need to reduce the angle at the centre so that the number of isosceles triangles is increased in order to increase the area of all the triangles in the circle. Reducing the angle at the centre resulted in increasing the number of triangles as can be seen from the work below involving number patterns.

With 120 triangles, area $=\frac{360}{3} \times 50 \sin 3^{0}=314.0157375$

With 360 triangles, area $=\frac{360}{1} \times 50 \sin 1^{0}=314.1433159$

With 3600 triangles, area $=\frac{360}{0.1} \times 50 \sin 0.1^{0}=314.1591059$

With 36000 triangles, area $=\frac{360}{0.01} \times 50 \sin 0.01^{0}=314.1592638$

With 360000 triangles, area $=\frac{360}{0.001} \times 50 \sin 0.001^{0}=314.1592653$

With 3600000 triangles, area $=\frac{360}{0.0001} \times 50 \sin 0.0001^{0}=314.1592654$

With 36000000 triangles, area $=\frac{360}{0.00001} \times 50 \sin 0.00001^{0}=314.1592654$

With 360000000 triangles, area $=\frac{360}{0.000001} \times 50 \sin 0.000001^{0}=314.1592654$

Looking at the patterns of the answers that have been obtained, the researchers concluded that with minimum of 3600 000 triangles inscribed in the circle with the angle at the centre being $0.0001^{0}$, the total sum of areas of the triangles will be equal to the area of the circle if calculated correct to 9 decimal places. This means that the formula for the area of the circle using $\sin 0.0001^{0}$ is:

Area of the circle $=\frac{1}{2} \mathrm{r}^{2} \sin \theta \times \frac{360}{\theta}$, where $\theta=10^{-\mathrm{n}}$ and $\mathrm{n}$ is the number of decimal places of $\pi$ required and $\mathrm{r}$ the radius of the circle.

If $\theta=0.0001^{0}$ and $\mathrm{r}$ the radius, then the area of the circle is:

$$
\begin{aligned}
\mathrm{A} & =\frac{1}{2} \times \mathrm{r}^{2} \times \frac{360}{0.0001} \times \sin 0.0001^{0} \\
& =\frac{1}{2} \times \mathrm{r}^{2} \times 3600000 \sin 0.0001^{0} \\
& =1800000 \mathrm{r}^{2} \sin 0.0001^{0} \\
& =1.8 \times 10^{6} \mathrm{r}^{2} \sin 0.0001^{0} \\
& =\left(1.8 \mathrm{r}^{2} \sin 0.0001^{0}\right) 10^{6}
\end{aligned}
$$




\subsection{Formula for the $n$th Decimal Places of $\pi$}

To derive the formula for $\pi$ since $\pi$ is an irrational number, let the area of the circle be equal to $1.8 \mathrm{r}^{2} \sin \theta \times 10^{\mathrm{n}+2}$ where $\theta$ is determined by the number of decimal places of $\pi$ required.

Comparing the two formulas for the area of the circle which are $\pi r^{2}$ and $1.8 r^{2} \sin \theta \times 10^{n+2}$, then

$$
\begin{array}{lll}
\pi \mathrm{r}^{2} & = & 1.8 \mathrm{r}^{2} \sin \theta \times 10^{\mathrm{n}+2}, \text { divide both sides by } \mathrm{r}^{2} \text { to get } \\
\pi & = & 1.8 \sin \theta \times 10^{\mathrm{n}+2}
\end{array}
$$

$\pi=\sin \theta\left(1.8 \times 10^{\mathrm{n}+2}\right)$ where $\theta=10^{-\mathrm{n}}$ and $\mathrm{n}$ the number of decimal places required of $\pi$. The general formula which is called Kwenge's formula for finding the nth number of decimal places of $\pi$ is:

$$
\pi=\sin \theta\left(1.8 \times 10^{\mathrm{n}+2}\right)
$$

where $\theta=10^{-\mathrm{n}}(10$ raised to the power negative $\mathrm{n})$ and $\mathrm{n}$ the number of decimal places of $\pi$ required.

\subsection{Theoretical Framework}

The study was guided by the theory of learning based on vision which according to Miller (1983) possess two stages of which the first stage is differentiation in which categorization and classification of information take place and the second stage being interpretation which involves synthesizing of knowledge for making conclusions and judgments about the newly integrated information. Besides these, for interpreting the information creativity plays an important role. Understanding and the meanings of visual can be enhanced due to creativity. Mathematics educators generally agree that knowledge of concepts is the foundation for intuitions and procedures and that a teacher should be concerned with the development of both conceptual and procedural knowledge. Lawler (1981) discussed that acquisition of mathematical knowledge require deep understanding of procedural and conceptual knowledge and relationship among them. Relationships can be established on two levels; understanding which originates from the ideas presented within the context and the relationships that are understood in an environment where appropriate abstractions have been made. The theoretical framework of this study described defines understanding in mathematics as the result of a process of making connections between ideas, facts, representations and procedures

Using number patterns in re-defining the meaning of the root of a number makes learners be involved in creativity. According to Sara Katz1 \& Moshe Stupel (2015), creativity is viewed as a property of cognitive process which tends to focus on analyzing the steps involved in creative thinking or in teaching creative cognitive processing. Creativity is about generating new and useful ideas and rules. Engagement in creativity would make learners be involved in producing something new and useful with respect to the previous knowledge. For Sara et al (2015), creative work requires applying and balancing three abilities that can all be developed. The three abilities are; synthetic, the analytic, and the practical abilities: Synthetic ability is the ability to generate novel and interesting ideas (Sara et al, 2015). Using number patterns would make learners be creative and good synthetic thinkers and at the same time be in the position to make connections between things that other people would not recognize without much involvement of the reasoning ability. Analytic ability is typically considered to be critical thinking ability. Learners with this skill analyze and evaluate ideas. According to social constructivist scholars, learning is viewed as an active process where learners should learn to discover principles, concepts and facts for themselves, hence the importance of encouraging guesswork and intuitive thinking in learners (Brown et al.1989).

\section{Methods}

Roots of perfect numbers were written down starting with perfect square numbers. The number of odd numbers determined by the square root starting with 1 were written in sequence. The odd numbers were added and the sums that were found formed a special sequence. The second step was writing down the cube roots and the cubes. Consecutive odd numbers determined by the cube root were written down that added up to the cube. This process continued up to nth root and nth perfect power. The last step was establishing the relationship among the roots, consecutive odd numbers and the perfect numbers.

\section{Results}

\subsection{Procedure for Establishing the Relationship between the Roots and the Odd Numbers}

Square roots, consecutive $n$ odd numbers and perfect square numbers 


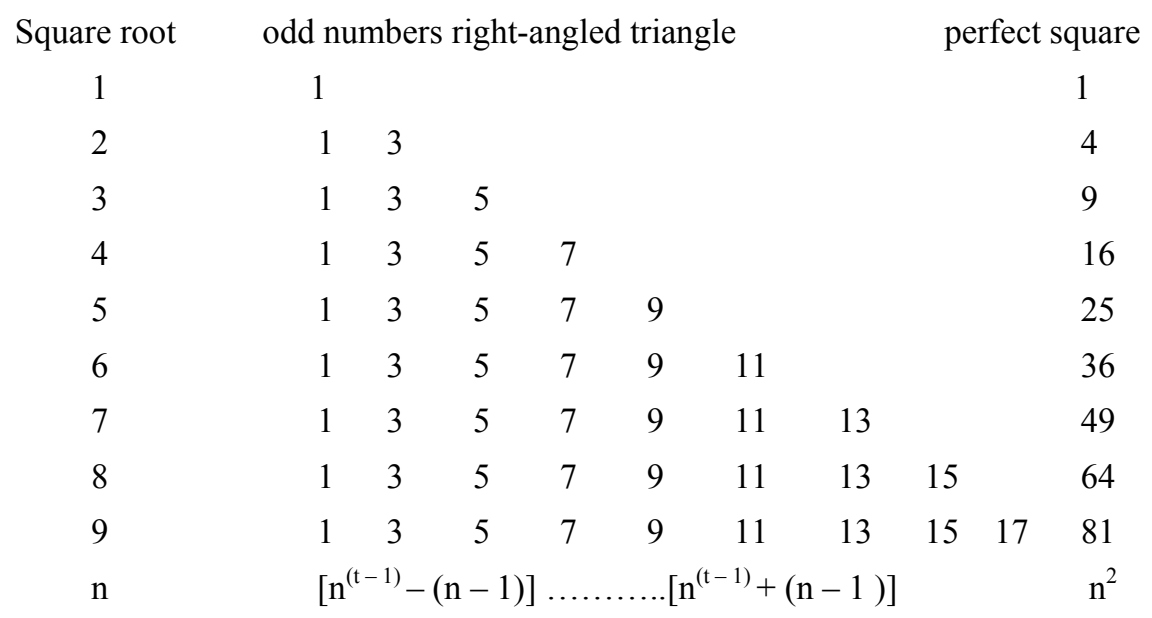

where $n$ is the square root and $t$ the power.

If $n$ is the root and $t$ the power of $n$,

then (i) the first term $=\left[n^{(t-1)}-(n-1)\right]$

(ii) the last term in the sequence $=\left[\mathrm{n}^{(\mathrm{t}-1)}+(\mathrm{n}-1)\right]$

The meaning of square root in terms of consecutive $n$ odd numbers. If the square root of $y$ is $x$, then it means that there are $x$ consecutive odd numbers starting with 1 which can add up to give the value of $y$. For example, if the square root of $y$ is 11 , then it means that there are 11 consecutive odd numbers that can be added to get the value of $y$. To find the first term of the consecutive 11 term, we use the formula; first term $=n^{(t-1)}-(n-1)$, where $n=11$ and $t$ $=2$. First term $=n^{(t-1)}-(n-1)$,

$$
\begin{aligned}
& =11^{(2-1)}-(11-1) \\
& =11-10 \\
& =1 .
\end{aligned}
$$

To find the remaining terms, we need to add 2 to the previous term.

So the second term $=1+2$

$$
=3
$$

Third term $=3+2$

$$
=5
$$

Fourth term $=5+2$

$$
=7
$$

Hence the required terms are: 1, 3, 5, 7, 9, 11, 13, 15, 17, 19, 21.

The sum of the above terms $=121$ which is the value of $y$.

The sum of the numbers in the row of the triangle is equal to a perfect square number of that row. The square root of 4 is 2 , this means that there are 2 consecutive odd numbers starting with 1 that can be added to get 4 . The square root of 9 is 3 , this means that there are 3 consecutive odd numbers starting with 1 that can be added to get 9 .

From the above consecutive odd numbers right-angled triangle, we can conclude that a perfect square number is the sum of the first $n$ consecutive odd numbers starting with 1(Kwenge, 2014).

Perfect squares and the sum of the terms between the first term and the last term of each sequence

Number (n)

Perfect squares $\left(\mathrm{n}^{2}\right)$

$\begin{array}{ccccc}1 & 2 & 3 & 4 & 5 \ldots \ldots \ldots \\ 1 & 4 & 9 & 16 & 25 \ldots \ldots \\ 0 & 3 & 8 & 15 & 24 \ldots \ldots \\ 3 & 5 & 7 & 9 & 11 \ldots\end{array}$

$\begin{array}{llllcc}\text { Sum of the terms in between }\left(\mathrm{n}^{2}-1\right) & 0 & 3 & 8 & 15 & 24 \ldots \ldots \\ \text { Difference between squares }(2 \mathrm{n}+1) & 3 & 5 & 7 & 9 & 11 \ldots\end{array}$

The purpose of learning or teaching this method is to help both the teacher and the learner to develop critical and analytical abilities that can help both the teacher and the learner to solve problems. This can also help both the 
learner and the teacher to improve their intellectual competences in logical reasoning, spatial visualization and abstract thought (Kwenge, 2014).

Studying the relationship between the odd numbers and the perfect squares, both the learner and the teacher can have the full understanding of the concept perfect square number and why these numbers are called perfect squares. The knowledge gained from the relationship between odd numbers and perfect square number can help the learner and the teacher to have deeper understanding of the concept irrational number which is a square root of a number which is not the sum of $n$ consecutive odd numbers starting with 1 other than saying that it is a number that cannot be expressed in form of a fraction.

\subsection{Square Roots of Perfect Square Numbers and Subtraction of Odd Numbers}

According to Brooksbank (www.murderuosmaths.co.uk/books/sqroot.html), the square root of a perfect square can be found by subtracting the odd numbers in order 1,3,5,7 etc. until you get to zero then count up the number of subtractions.

E.g. to get the square root of 36 it's:

$$
\begin{aligned}
36-1 & =35 \\
35-3 & =32 \\
32-5 & =27 \\
27-7 & =20 \\
20-9 & =11 \\
11-11 & =0
\end{aligned}
$$

Total number of subtractions $=6$ therefore the square root of $36=6$.

To find the perfect square number, $\mathrm{n}$ consecutive odd numbers are added starting with 1 , so to find the square root, start subtracting odd numbers from the perfect square, starting always with 1 until you get 0 .

Let's start the process;

$$
\begin{aligned}
& 4-1=3 \\
& 3-3=0 .
\end{aligned}
$$

When you get 0 , stop the process of subtracting and count the odd numbers that have been subtracted to get 0 .

In this case, we have 2 odd numbers subtracted; this means that 2 is the square root of 4 .

What is the square root of 25 ?

$$
\begin{gathered}
25-1=24, \\
24-3=21, \\
21-5=16, \\
16-7=9, \\
9-9=0 .
\end{gathered}
$$

How many odd numbers have been subtracted to get 0 ? They are 5 , so the square root of 25 is 5 .

\subsection{Negative Square Roots}

The square root of 4 is 2 because if you add the first 2 odd numbers starting with 1 , the answer is 4 . Why is -2 , a square root of 4 ? Let us look at the addition of consecutive negative odd numbers starting with -1 .

$$
\begin{aligned}
& -1=-1=-(1) \\
& -1+(-3)=-4=-(4) \\
& -1+(-3)+(-5)=-9=-(9) \\
& -1+(-3)+(-5)+(-7)=-16=-(16)
\end{aligned}
$$

If you add the first 2 negative numbers, the answer is -4 . Hence -2 is a square root of 4

$$
\begin{aligned}
-4 & =-(4), \text { so }-(\sqrt{ } 4)=-(2)=-2 \\
-9 & =-(9), \text { so }-(\sqrt{ } 9)=-(3)=-3 \\
-16 & =-(16), \text { so }-(\sqrt{ } 16)=-(4)=-4
\end{aligned}
$$




$$
-1-3-5-7=-(1+3+5+7)=-(16)
$$

The above pattern explains why negative numbers are square roots of positive numbers.

When the sum of the first consecutive odd numbers is on the left hand side of zero, then the square root of such the sum will be negative. Telling the learner that -2 squared is 4 , is not enough. There is need to explain how -2 when squared changes to positive 4 and why should the square root of 4 be -2 .

\subsection{Cubes and Cube Roots}

The diagram below is according to Musser L. G, Burger F.W and Peterson E.B (2004)

$$
\begin{array}{ccc}
1 & = & 1 \\
3+5 & = & 8 \\
7+9+11 & = & 27 \\
13+15+17+19 & = & 64 \\
21+23+25+27+29 & = & 125 .
\end{array}
$$

\begin{tabular}{|c|c|c|c|c|c|c|}
\hline Cube root & \multicolumn{5}{|c|}{ odd numbers right-angled triangle } & cube \\
\hline 1 & \multicolumn{5}{|l|}{1} & 1 \\
\hline 2 & 3 & \multicolumn{4}{|l|}{5} & 8 \\
\hline 3 & 7 & 9 & \multicolumn{3}{|c|}{11} & 27 \\
\hline 4 & 13 & 15 & 17 & \multicolumn{2}{|l|}{19} & 64 \\
\hline 5 & 21 & 23 & 25 & 27 & 29 & 125 \\
\hline 6 & 31 & 33 & 35 & 37 & $39 \quad 41$ & 216 \\
\hline $\mathrm{n}$ & \multicolumn{6}{|c|}{$\left[\mathrm{n}^{(\mathrm{t}-1)}-(\mathrm{n}-1)\right] \ldots \ldots \ldots \ldots\left[\mathrm{n}^{(\mathrm{t}-1)}+(\mathrm{n}-1)\right]$} \\
\hline
\end{tabular}

If we look at the triangle, all the numbers are odd and the sum of each row is equal to the number which is a cube. When a whole number is multiplied three time, the product is called a cube. Rearranging the triangle above, the following results were obtained which show that there is a special relationship between $n$ consecutive odd numbers and cubes.

where $n$ is the cube root and $t$ the power.

If $t$ is the power and $n$ the root,

then the first term $=\left[\mathrm{n}^{(\mathrm{t}-1)}-(\mathrm{n}-1)\right]$ and last term $=\left[\mathrm{n}^{\mathrm{t}-1)}+(\mathrm{n}-1)\right]$

If the cube root is $\mathrm{n}$, then there are $\mathrm{n}$ consecutive odd numbers whose sum is the cube and the common difference of the sequence is 2 .

Hence the cube is the sum of $n$ consecutive odd numbers with the first term being $\left[n^{(t-1)}-(n-1)\right]$ where $t=3$ and last term being $\left[\mathrm{n}^{\mathrm{t}-1)}+(\mathrm{n}-1)\right]$ and common difference being 2

Similarities between the cubes and perfect square numbers.

(i) Both are sums of $n$ consecutive odd numbers.

(ii) The consecutive $n$ odd numbers of both can be expressed in form of a right-angled triangle.

Differences between the cubes and perfect square numbers

(i) The perfect square number is a sum of $n$ consecutive odd numbers starting with 1 where $n$ is the square root while the cube is the sum of $n$ consecutive odd numbers with the first term being $n^{2}-n+1$ and the last term being $n^{2}+n-1$ where $n$ is the cube root.

(ii) A cube is a product of a whole number multiplied by itself three times while a perfect square number is a product of a whole number multiplied by itself twice.

Finding consecutive odd numbers that add up to a cube

To find the first consecutive odd number needed to find the cube, use the formula: $n^{2}-n+1$ and to find the next odd number, add 2 to $n^{2}-n+1$ and then keep on adding 2 to find the next term of the sequence.

Example 1

Find the consecutive odd numbers that can be added to get the cube root 8 .

First odd number: $\mathrm{n}^{2}-\mathrm{n}+1$. 
Last odd number: $\mathrm{n}^{2}+\mathrm{n}-1$

First odd number in the sequence, $\mathrm{n}^{2}-\mathrm{n}+1=8^{2}-8+1$

$$
\begin{aligned}
& =\quad 64-8+1 \\
& =56+1 . \\
& =57
\end{aligned}
$$

Last odd number in the sequence: $\quad \mathrm{n}^{2}+\mathrm{n}-1=8^{2}+8-1$

$$
\begin{aligned}
& =\quad 64+8-1 \\
& =72-1 \\
& =71
\end{aligned}
$$

To find the next term or number in the sequence add 2 the first term and the terms that follow.

Since the first term is 57 , then next term is $57+2=59$, next is $59+2=61$ until 71 is obtained

Terms needed are: $57,59,61,63,65,67,69,71$.

Sum of terms: $\quad 57+59+61+63+65+67+69+71=512$

The cube root of 512 is 8

Example 2

If $\mathrm{x}$ is the cube root of $\mathrm{y}$ and $\mathrm{x}=9$, find the $\mathrm{x}$ consecutive odd numbers whose sum is $\mathrm{y}$.

First odd number in the sequence: $\mathrm{n}^{2}-\mathrm{n}+1=9^{2}-9+1$

$$
\begin{aligned}
& =81-9+1 \\
& =72+1 \\
& =73 .
\end{aligned}
$$

Last odd number in the sequence: $\mathrm{n}^{2}+\mathrm{n}-1=9^{2}+9-1$

$$
\begin{aligned}
& =81+9-1 \\
& =89 .
\end{aligned}
$$

Since the first term is 73 , then next terms are obtained by adding 2 to each term

The consecutive odd numbers are: $73,75,77,79,81,83,85,87,89$.

The expression $x^{3}$ means $x$ raised to the power 3 and if simplified $x$ becomes the cube root and this means that there are $\mathrm{x}$ consecutive odd numbers that can be added to get the cube.

\section{Example 3}

If $x$ is the square root of $y$ and $x=6$, find the $x$ consecutive odd numbers whose sum is $y$ and hence state the value of $y$.

The first term is always 1 while the last term is obtained using $2 n-1$ where $n$ is the square root.

The last term $=2 n-1$, where $n=6$, since 6 is the square root.

$$
\begin{aligned}
& =2 \times 6-1 \\
& =12-1 \\
& =11 .
\end{aligned}
$$

Since the first term is 1 , then the other terms are; $3,5,7,9,11$ because the common difference is 2 . Hence the required consecutive terms are: $1,3,5,7,9,11$.

The value of $y=1+3+5+7+9+11=36$.

The expression $x^{2}$ is a perfect square while $x$ is the square root and $x$ is also the number of consecutive odd numbers needed to get the perfect square starting with 1 . 


\subsection{Relationship between $4^{\text {th }}$ Power and Consecutive $n$ Odd Numbers}

$\begin{array}{llc}\text { fourth root } & \text { consecutive odd numbers } & \mathrm{n}^{4} \\ 1 & 1 & 1 \\ 2 & 7,9 & 16 \\ 3 & 25,27,29 & 81 \\ 4 & 61,63,65,67 & 256 \\ 5 & 121,123,125,127,129 & 625 \\ \mathrm{n} & {\left[\mathrm{n}^{(\mathrm{t}-1)}-(\mathrm{n}-1)\right], \ldots \ldots \ldots \ldots \ldots,\left[\mathrm{n}^{(\mathrm{t}-1)}+(\mathrm{n}-1)\right]} & \mathrm{n}^{\mathrm{t}}\end{array}$

If $n$ is the root and $t$ the power of $n$, then

(i) the first term $=\left[\mathrm{n}^{(\mathrm{t}-1)}-(\mathrm{n}-1)\right]$,

(ii) the last term in the sequence $=\left[\mathrm{n}^{(t-1)}+(\mathrm{n}-1)\right]$,

In the relationship of the $n$th root which is a whole number, the first term of the Arithmetic Progression $=\left[n^{(t-1)}-\right.$ $(n-1)]$ while the last term is obtained by $\left[\mathrm{n}^{(\mathrm{t}-1)}+(\mathrm{n}-1)\right]$ and 2 is the common difference of this AP.

If 6 is the $4^{\text {th }}$ root of $y$, find 6 consecutive odd numbers whose sum is equal to $y$.

$$
\begin{array}{ll}
\text { First term } & =\left[\mathrm{n}^{(\mathrm{t}-1)}-(\mathrm{n}-1)\right], \text { where } \mathrm{n}=6, \\
\text { The first term } & =\left[6^{(4-1)}-(6-1)\right] \\
& =6^{3}-5 \\
& =216-5 \\
& =211
\end{array}
$$

Since the first term is 211 , add 2 to 211 to get the second term, so that the second term $=211+2$

which is 213 . Continue the process for other remaining terms.

The required 6 consecutive odd numbers are; 211, 213, 215, 217, 219, 221.

The sum of the above sequence $=1296$ which is the value of $y$.

If $n$ is the fourth root of $y$, then there are $n$ consecutive odd numbers that will add up to $y$.

Example 1.

The fourth root of 16 is 2 . This means that there are 2 consecutive odd numbers that will add up to 16 which are 7 and 9.

Example 2.

The fourth root of 256 is 4 . This means that there are 4 consecutive odd numbers that will add up to 256 and these are; $61,63,65,67$.

\subsection{Power 5 and Odd Numbers}

$\begin{array}{llc}\text { fifth root } & \text { consecutive odd numbers } & \mathrm{n}^{5} \\ 1 & 1 & 1 \\ 2 & 15,17 & 32 \\ 3 & 79,81,83 & 243 \\ 4 & 253,255,257,259 & 1024 \\ \mathrm{n} & {\left[\mathrm{n}^{(\mathrm{t}-1)}-(\mathrm{n}-1)\right], \ldots \ldots \ldots,\left[\mathrm{n}^{(\mathrm{t}-1)}+(\mathrm{n}-1)\right]} & \mathrm{n}^{\mathrm{t}}\end{array}$

If $n$ is the root and $t$ the power of $n$, then

(i) the first term in the sequence $=\left[\mathrm{n}^{(\mathrm{t}-1)}-(\mathrm{n}-1)\right]$,

(ii) the last term in the sequence $=\left[\mathrm{n}^{(\mathrm{t}-1)}+(\mathrm{n}-1)\right]$,

The general formula for the number of $n$ consecutive odd numbers that can add up to $n^{t}$

(i) first term in the sequence $=\left[\mathrm{n}^{(\mathrm{t}-1)}-(\mathrm{n}-1)\right]$,

(ii) last term in the sequence $=\left[\mathrm{n}^{(\mathrm{t}-1)}+(\mathrm{n}-1)\right]$ and the common difference for the 
arithmetic progression is 2 .

\section{Discussion}

The findings in the study would help the learners and teachers understand the relationship that exists between consecutive odd numbers and the roots of perfect numbers and why some numbers are called perfect. The number patterns and worked examples showed that there was a special relationship between the $n$th root of the perfect number which is a whole number and the consecutive $n$ odd numbers. This special relationship defines the meaning of nth root that if $n$ is the root of $\mathrm{y}$, then it means that there are $n$ consecutive odd numbers that can add up to get $\mathrm{y}$ with the first term being equal to [n $\left.{ }^{(t-1)}-(n-1)\right]$, where $n$ is the root and $t$ the power other than multiplying the root $n$ times to get y. The relationship that has been established in the study will enable the learners and teachers to understand the concept root fully from both multiplication and addition points of view. The results of the study in terms of the formulas shows that arithmetic progression and perfect numbers are related. When teaching mathematics, the teacher should form an adequate model of the pupils' ways of viewing an idea and then construct a tentative path on which pupils may move to construct a mathematical idea in line with accepted knowledge (Lyn, 2002). If the teacher lacks the content knowledge, then he cannot engage the pupils into the process of mathematical thinking instead he would engage them into what is called the product of mathematical thought (Skemp, 1971). Mathematics is taught to enable the learner to acquire the knowledge and understanding of fundamental facts and issues on the studying of mathematics and form the base from which to explore concepts and develop problem-solving skills (Davis, 1980). Through knowledge and understanding learners develop mathematical reasoning to make deductions, use appropriate mathematical concepts, skills and apply general rules correctly to solve problems in both familiar and unfamiliar situations including those in real-life.

Mathematics is taught so that learners can use investigating patterns which allow them to experience the excitement and satisfaction of mathematical discovery. Mathematical inquiry encourages students to become risk-takers, inquirers and critical thinkers. Through the use of mathematical investigations, learners are given the opportunity to apply mathematical knowledge and problem-solving techniques to investigate a problem, generate ideas or rules, analyse information, find relationships and patterns, describe these mathematically as general rules, and justify or prove them. The 1968 and 1986 National Policies of Education spoke in the same tone as the Kothari Commission report and the 1986 policy states that "mathematics should be visualized as the vehicle to train a child to think, reason, analyze and articulate logically. Apart from being a specific subject, it should be treated as a concomitant to any subject involving analysis and reasoning" (Government of India-Ministry of Human Resource Development, 1998, p.29). Using number patterns can help learners and teachers acquire skills in thinking, reasoning, analyzing and articulating issues logically. The higher aim is to develop the child's resources to think and reason mathematically, to pursue assumptions to their logical conclusion and to handle abstraction. It includes a way of doing things, and the ability and the attitude to formulate and solve problems." (NCERT, 2005, p. 42) The understanding is also that better conceptual understanding of mathematics involves exploring the relationship that one set of numbers has with the other set of numbers as well. Like in this case the set of perfect numbers and the set of consecutive odd numbers.

Generally, the teacher believes that mathematics is about knowing solutions to problems and not about being able to understand what the concept means and about being able to think of ways of solving problems. The emphasis is on the 'correct answer' rather than on thinking of a variety of ways to approach the solution. The explanation on the relationship between the consecutive $n$ odd numbers and the numbers with roots which are whole numbers which has been expressed in terms of the two formulas, which states that if the root of $n$ is $x$, where $x$ is a whole number and $n$ can be expressed in index form with the power being a whole number, then it means that there are $x$ consecutive odd numbers that add up to $n$. This explanation is the Kwenge-Mwewa root theory on the relationship that exists between $n$ consecutive odd numbers and the roots of perfect numbers. A perfect number is number whose root is a whole number.

\section{Conclusion}

If learners have to learn best, they need to be exposed to the use of a wide range of teaching methods (Portman $\mathrm{J}$ and Richardson, 1997) which should include using number patterns to establish relationships among various groups or sets of numbers. Investigating patterns allows students to experience the excitement and satisfaction of mathematical discovery. Mathematical inquiry encourages students to become risk-takers, inquirers and critical thinkers.

Through the use of mathematical investigations on number patterns, learners are able to apply mathematical knowledge and problem-solving techniques to investigate a problem, generate ideas or rules, analyse the information, 
establish relationships among numbers with the help of number patterns and describe these mathematically as general rules, and justify or prove them. Studying the relationship between the consecutive odd numbers and perfect numbers can make both the teacher and the learner to have a full understanding of the meaning of the concept $n$th root of any given number (Kwenge, 2014). Knowledge and understanding are fundamental to studying mathematics and form the base from which to explore concepts and develop problem-solving skills. Through knowledge and understanding students develop mathematical reasoning to make deductions and solve problems.

Learners should be encouraged to explore the numbers so that they can discover the hidden powers in them and use them in solving the problems being encountered in everyday life and be able to understand the universe we live in. Teachers of mathematics should try by all means to use models, number patterns and other teaching aids when teaching mathematics because at times mathematics tends to be full of abstract which simple minds cannot perceive without difficulties. Numbers being defined as ideas have unique characteristic which teachers of mathematics need to explore because whatever exists has elements of numbers. There is nothing that exists without numbers.

\section{Acknowledgement}

This article is dedicated to the warm relationship which the researchers enjoyed when they were pursuing their masters degree in Mathematics Education at the Copperbelt University in Zambia.

\section{References}

Brown T., McNamara O., Olwen H., \& Jones L. (1989). Primary Student Teacher Understanding of Mathematics and its Teaching. British Educational Research Journal, 29, 299-323.

Davis, P.J., \& Hersh, R. (1980). The Mathematical Experience. Boston: Birkhauser.

Foster G. A., Winters L. J., Gell J. M., Rath J. N., \& Gordon B.W. (1995). Merrill Algebra 1 Applications and Connections. New York: Glencoe/McGraw-Hill.

Foster G.A., Winters L J., \& Rath J.N. (1986). Merrill Algebra Two with Trigonometry. Ohio: Merrill Publishing Co.

Government of India (GOI)-Ministry of Human Resource Development (MHRD). (1998). National Education Policy 1986 as revised in 1992 and National Education Policy 1968. New Delhi: New Delhi:GOI-MHRD.

Kwenge E. (2013). Deriving the formula for $\pi$ and its application. Zambia Journal of Teacher Professional Growth, $1(1), 116-127$.

Kwenge E. (2014). Factors affecting the teaching and learning of mathematics without calculators in secondary schools in Zambia: A case study of 6 secondary schools in Mpika District. Journal of Education and Practice, 5(22), 74-80.

Kwenge Erasmus. (2014). Teaching and learning of Mathematics without calculators. Berlin: LAP LAMBERT Academic Publishing.

Lankford F.G., Ulrich J.F., \& Clark J.R. (1961). Essential Mathematics. New York: Harcourt, Brace \& World, Inc.

Lawler, R. W. (1981). The progressive construction of mind. Cognitive Science, 5, 1-30. http://dx.doi.org/10.1111/j.1551-6708.1981.tb00867.x

Lyn. O.E. (2002). Handbook of International Researches in Mathematics Education. London: Lawrence Erlbaum Associates Publishers Inc.

Millar, R., \& Driver, R. (1983). Beyond process. Studies in Science Education, 14, 31-62.

National Council of Teachers Of Mathematics (2000). Enrichment Mathematics for the Grades, Twenty-seventh year book. Washington D.C.

Moyer, P. S., \& Milewicz, E. (2002). Learning to question: Categories of questioning used by preservice teachers during diagnostic mathematics interviews. Journal of Mathematics Teacher Education, 5(4), 293-315. http://dx.doi.org/10.1023/A:1021251912775

Musser L.G., Burger F.W., \& Peterson E.B. (2004). Essentials of Mathematics For Elementary Teachers A Contemporary Approach. New Jessey: John Wiley \& Sons, Inc.

National Council of Educational Research and Training, (2005). National Curriculum Framework 2005. New Delhi: NCERT. 
Roland E. L., Timothy D. K., \& Lee S. (1998). Heath Algebra 1 An integrated Approach. Boston: McDougal Littell.

Sara Katz \& Moshe Stupel. (2015). Promoting Creativity and Self-efficacy of Elementary Students through a Collaborative Research Task in Mathematics: A Case Study. Journal of Curriculum and Teaching, 4(1), 68-82.

Shulman, L. (1987). Knowledge and Teaching. Harvard Educational Review, 57(1), 1-22. http://dx.doi.org/10.17763/haer.57.1.j463w79r56455411

Skemp, R. R. (1976). Relational understanding and instrumental understanding. Mathematics Teaching, 77, 20-26.

Zuya E. H. (2014). Mathematics Teachers' Ability to Investigate Students' Thinking Processes About Some Algebraic Concepts. Journal of Education and Practice, 5(25), 117-122. 